\title{
A review of $B$ lymphocytes in tumour immune response
}

\author{
Nuri E Goret ${ }^{1,5}$, Ceren C Goret ${ }^{2,5 *}$, Ugur Topal ${ }^{1,5}$ and Omer F Ozkan ${ }^{4,5}$ \\ ${ }^{1}$ Department of General Surgery, Health Sciences University, Kartal Dr Lütfi Kırdar Research and Education Hospital, Istanbul, Turkey \\ ${ }^{2}$ Department of Surgical Pathology, Health Sciences University, Sancaktepe Research and Education Hospital, Istanbul, Turkey \\ ${ }^{3}$ Department of Surgical Oncology, Erciyes University Research and Application Hospital, Kayseri, Turkey \\ ${ }^{4}$ Department of General Surgery, Health Sciences University, Umraniye Research and Education Hospital, Istanbul, Turkey \\ ${ }^{5}$ Department of General Surgery, Health Sciences University, Molecular Oncology, Istanbul, Turkey
}

\begin{abstract}
$\mathrm{B}$ cells have often been ignored in tumor immunology for years, with the idea that humoral and cytolytic responses work against each other; instead CD8+ T lymphocytes were focused on for tumor immunology, because of their ability to directly kill tumor cells.

In studies conducted to date, the role of B lymphocytes in tumor immunity has been largely unclear, and the results from the research groups are controversial; nowadays, many antitumor responses of B cells have been determined and molecular mechanisms have been tried to be defined.

B cells are phenotypically and functionally heterogeneous and have been reported to play an important role in the antitumor response.

An understanding of the molecular mechanisms of B cells in tumor immunology and the characterization of the functions of B cells will help to develop new clinical strategies for cancer immunotherapy, as well as be a guide to predict the clinical outcomes of patients with carcinoma and to identify more effective treatments.
\end{abstract}

\section{Introduction}

B lymphocytes were first identified in birds. Following the removal of bursas in chicks, the ability to produce antibodies in chickens has been found to be severely impaired [1]. A decade later, it was found that mammalian B cells were obtained from the bone marrow and plasma cells, the source of antibodies, developed from B cells [2].

Over the years, most of the studies on B cell function in the immune response have focused on antigen presentation and antibody production. It has also been shown that B lymphocytes can act as effector or regulatory cells [3].

$\mathrm{B}$ cells have often been ignored in tumor immunology for years, with the idea that humoral and cytolytic responses work against each other [4]. In tumor immunology, due to the frequent presence of CD8 + T lymphocytes in peritumoral lymphocytic infiltration, these cells were thought to be associated with surveillance in patients with carcinoma. There was a focus on CD8 + T lymphocytes due to their ability to directly kill tumor cells [5].

In a study of 80 patients with soft tissue sarcomas in 2012, high CD20 + peritumoral B lymphocyte density was reported as an independent negative prognostic indicator for these cases and further investigation was reported to be needed to determine if they would increase metastatic potential [6].

In a study in 2018, it was reported that tumor infiltrating B cells (TIL-B) in breast carcinoma were not positively or negatively important in humoral and cellular immunity, and that IL-10 secreted from antibodies and B lymphocytes was involved in the process, and that TIL-B are potentially binding to lymphocytes and have immune checkpoint inhibitor effects [7].

In studies conducted to date, the role of B lymphocytes in tumor immunity remains largely unclear and controversial [1].
In this review, we discuss the role of B cells in tumor immunology, which may positively or negatively affect patients with carcinoma.

\section{Classification}

In tumor immunology, B cells can be classified in 4 groups according to Li et al. [1].

\section{CD40-Activated B (CD40-B) Cells \\ Tumor Killer B Cells \\ Tumor-Infiltrating B Cells (TIL-Bs) \\ Resting and Regulatory B Cells \\ CD40-activated B (CD40-B) cells}

CD40-B cells are thought to be an excellent source of professional antigen-presenting cell (APC) for antigen-specific tumor immunotherapy. Many studies have shown that it has strong effects on carcinoma immunotherapy. CD40-B cells provide strong expansion of antigen-specific CD4 and CD8 positive T cells, including naïve CD8 positive T cells. They induce T cell proliferation, interferon- $\gamma($ IFN- $\gamma$ ) production, and specific cytotoxic T lymphocyte (CTL) responses $[8,9]$.

In mouse models, CD40-B cells have been shown to present antigen to pure $\mathrm{CD} 8$ positive $\mathrm{T}$ cells to induce the formation of strong

${ }^{\star}$ Correspondence to: Ceren Canbey Goret, Department of Surgical Pathology, Sancaktepe Research and Education Hospital, Health Sciences University, Floor 0, Istanbul, Turkey, Tel: +905079500212; E-mail: drcerencanbey@hotmail.com

Key words: B lymphocyte, TIL-B, tumor killer B cells, Bregs, CD40 activated B cells Received: March 07, 2019; Accepted: March 22, 2019; Published: March 25, 2019 
T-effectors that can directly secrete cytokines and kill target cells. In addition, it has been shown that CD40-B lymphocytes can co-localize with $\mathrm{T}$ cells in $\mathrm{T}$ lymphocyte-rich regions of secondary lymphoid organs by expressing some molecules $[9,10]$. This condition would facilitate CD40-B cell and T cell contact for antigen presentation.

Li et al. [11] demonstrated an antitumor activity enhanced by a tumor-draining lymph node stimulated by anti-CD40 monoclonal antibody in their study with a metastatic mouse model. Luchi et al. [12] reported in their study that host $\mathrm{B}$ cells are required for $\mathrm{T}$ cells adapted to mediate optimal antitumor immunity.

\section{Tumor killer B cells}

B cells can directly kill tumor cells by means of mechanisms independent of antibodies. Recent studies have shown that B cells express death-causing ligands and thus can mediate cell death in many cases [1].

B cells were shown to be directly cytotoxic against tumor cells with Fas ligand, tumor necrosis factor-associated apoptosis-inducing ligand (TRAIL), programmed death ligands 1 and 2 (PD-L1 and PDL2) and granzyme B (GrB). B cells can produce antibodies that lead to CDC (Complement-dependent cytotoxicity) and ADCC (Antibodydependent cellular cytotoxicity). In addition to B cells' ability to directly kill tumor cells by means of mechanisms independent of antibodies, it is also thought that functionally sensitized and activated B cells may function as effector cells to mediate antitumor immunity [13-16].

Li et al. [17] reported that sensitized and activated B cells mediated tumor regression in cancer immunotherapy and activated B cells were then transferred to tumor-bearing receptors for treatment and this significantly reduced lung metastases.

\section{Tumor-infiltrating B cells (TIL-Bs)}

TIL-Bs are controversial in antitumor immunity. TIL-Bs were detected in many malignancies. Some studies have reported that the presence of TIL-Bs is associated with increased survival, low recurrence rates, and low metastasis rates $[1,18]$.

In a study with high grade serous ovarian carcinoma, the presence of intraepithelial CD20 + TIL-Bs was associated with disease-specific survival, and the relationship between immune infiltrates and survival was also reported to be related to the histological subtype [19]. Mahmoud et al. [20] in their study of different histological subtypes, obtained positive results in the presence of CD20 + TIL-Bs.

On the other hand, TIL-Bs can produce cytokines that contribute to tumor development. TIL-Bs in prostate carcinoma have been reported to produce an inflammatory lymphotoxin, followed by the activation of STAT3 in tumor cells. In this study, B cell infiltration was detected in $100 \%$ of human prostate carcinoma samples and B cells could not be detected in normal prostate or benign prostatic hyperplasia samples [21].

Similarly, another study reported that tumor infiltrating $\mathrm{T}$ and $\mathrm{B}$ cells were not associated with long-term survival of non-small cell lung cancer patients [18].

\section{Resting and regulatory $B$ cells}

In contrast to activated $\mathrm{B}$ cells, there have been many reports suggesting that resting $B$ cells will support the development or progression of cancer. Resting B cells are small B cells at the G0 stage of the cell cycle prior to activation. Studies have shown increased effector T cells, $\mathrm{T}$ cell infiltration of tumors, increased Thl cytokine and antitumor CTL response, and even decreased T regulatory cell (Treg) frequencies in B cell deficient mice. NK cell antitumor activity has also been reported, but the mechanisms are not fully understood [22-24].

In some studies, it has been reported that $\mathrm{B}$ cells in the preparation phase cause $\mathrm{CD} 4+\mathrm{T}$ cell deactivation for CTL-mediated tumor immunity [23]. The effects of B cells on antitumor immunity are assumed to be dependent on the presence of B-cell subsets, which are mainly located under certain tumor conditions.

Mizoguchi et al. demonstrated that IL-10-producing B cells, which they named regulatory B cells (Bregs) may suppress inflammatory responses in experimental autoimmune encephalomyelitis, collageninduced arthritis, and colitis [25].

In most of these studies, while Bregs has functions related to IL10 production, their mechanisms have still not been identified due to conflicting results regarding the phenotypic characterization of IL-10 producing cells. IL-10 is an immunomodulatory cytokine and inhibits Th1 polarization, prevents Th2 responses, and suppresses proinflammatory cytokine production by monocytes and macrophages. So far, the role of Bregs in tumor immunology is unclear, but several studies suggest that Bregs can negatively regulate antitumor immunity [1].

In the mouse carcinogenesis model, Schioppa et al. found an association with an increase in IFN-y producing CD8 + T cells in the spleen, and a significant reduction in B-regulatory cells producing IL-10 [26].

In another study, Horikawa et al. reported that lymphoma inhibited deposition during CD20 immunotherapy in mice which produced IL10 by Breg [27].

Bregs also causes differentiation of the Tregs. It has been shown that IL-10 produced by Bregs in various disease models is important to produce Tregs [28].

\section{Conclusion}

$\mathrm{B}$ cells are phenotypically and functionally heterogeneous and play a role in tumor immunity. The literature shows that B cells play an important role in the antitumor response.

\section{B cells}

- present tumor antigens to $\mathrm{T}$ cells, in order to create antitumor cytotoxic T lymphocytes.

- with the tumor antigen stimulus, can convert into plasma cells to create antibodies targeting tumor cells through antibody-dependent cellular cytotoxicity (ADCC) and/or complement-dependent cytotoxicity (CDC) pathways.

- can serve as killer cells, in the absence of antibodies, to directly cause tumor lysis.

- migrates to tumor tissue and can become TIL-Bs, which can induce humoral immune response or function as local killer cells.

- decrease antitumor reactions by creating the immunomodulator cytokine IL-10, by suppressing Th1 immune response and increasing Treg and $\operatorname{Tr} 1$ response.

An understanding of the molecular mechanisms of B cells in tumor immunology and the characterization of the functions of B cells will help to develop new clinical strategies for cancer immunotherapy, as well as be a guide to predict the clinical outcomes of patients with carcinoma and to identify more effective treatments. 


\section{References}

1. Li Q, Pan Q, Tao H, Zhang XL, Huang S, Chang AE (2015) B Cells in Cancer Immunology: For or Against Cancer Growth? Cancer Immunol: 47-61.

2. Mauri C, Ehrenstein MR (2008) The 'short' history of regulatory B cells. Trends Immunol 29: 34-40. [Crossref]

3. Mizoguchi A, Bhan AK (2006) A case for regulatory B cells. J Immunol 176: 705-710. [Crossref]

4. Linnebacher M, Maletzki C (2012) Tumor-infiltrating B cells: The ignored players in tumor immunology. Oncoimmunology 1: 1186-1188.

5. Dushyanthen S, Beavis PA, Savas P, Teo ZL, Zhou C, et al. (2015) Relevance of tumorinfiltrating lymphocytes in breast cancer. BMC Med 13: 202.

6. Sorbye SW, Kilvaer TK, Valkov A, Donnem T, Smeland E, et al. (2012) Prognostic impact of peritumoral lymphocyte infiltration in soft tissue sarcomas. BMC Clin Pathol 12: 5.

7. Shen M, Wang J, Ren X (2018) New Insights into Tumor-Infiltrating B Lymphocytes in Breast Cancer: Clinical Impacts and Regulatory Mechanisms. Front Immunol 9: 470. [Crossref]

8. Guo S, Xu J, Denning W, Hel Z (2009) Induction of protective cytotoxic T-cell responses by a B-cell- based cellular vaccine requires stable expression of antigen. Gene Ther 16: 1300-1313. [Crossref]

9. Mathieu M, Cotta-Grand N, Daudelin JF, Boulet S, Lapointe R, et al. (2012) CD40activated $\mathrm{B}$ cells can efficiently prime antigen-specific naive $\mathrm{CD} 8+\mathrm{T}$ cells to generate effector but not memory T cells. PLoS One 7: e30139. [Crossref]

10. von Bergwelt-Baildon M, Shimabukuro-Vornhagen A, Popov A, Klein-Gonzalez N, Fiore $\mathrm{F}$, et al. (2006) CD40-activated B cells express full lymph node homing triad and induce T-cell chemotaxis: potential as cellular adjuvants. Blood 107: 2786-2789. [Crossref]

11. Li Q, Grover AC, Donald EJ, Carr A, Yu J, et al. (2005) Simultaneous targeting of CD3 on T cells and CD40 on B or dendritic cells augments the antitumor reactivity of tumorprimed lymph node cells. J Immunol 175: 1424-1432. [Crossref]

12. Luchi T, Teitz-Tennenbaum S, Huang J, Redman BG, Hughes SD, et al. (2008) Interleukin-21 augments the efficacy of T-cell therapy by eliciting concurrent cellular and humoral responses. Cancer Res 68: 4431-4441.

13. Zhong X, Tumang JR, Gao W, Bai C, Rothstein TL (2007) PD-L2 expression extends beyond dendritic cells/ macrophages to B1 cells enriched for $\mathrm{V}(\mathrm{H}) 11 / \mathrm{V}(\mathrm{H}) 12$ and phosphatidylcholine binding. Eur J Immunol 37: 2405-2410. [Crossref]

14. Hagn M, Ebel V, Sontheimer K, Lunov O, Beyer T, et al. (2010) CD5+ B cells from individuals with systemic lupus erythematosus express granzyme B. Eur J Immunol 40: 2060-2069. [Crossref]

15. Lundy SK (2009) Killer B lymphocytes: the evidence and the potential. Inflamm Res 58: 345-357. [Crossref]
16. Hagn M, Schwesinger E, Ebel V, Sontheimer K, Maier J, et al. (2009) Human B cells secrete granzyme $\mathrm{B}$ when recognizing viral antigens in the context of the acute phase cytokine IL-21. J Immunol 183: 1838-1845. [Crossref]

17. Li Q, Teitz-Tennenbaum S, Donald EJ, Li M, Chang AE, et al. (2009) In vivo sensitized and in vitro activated B cells mediate tumor regression in cancer adoptive immunotherapy. J Immunol 183: 3195-13203. [Crossref]

18. Dieu-Nosjean MC, Antoine M, Danel C, Heudes D, Wislez M, et al. (2008) Longterm survival for patients with non-small-cell lung cancer with intratumoral lymphoid structures. J Clin Oncol 26: 4410-4417. [Crossref]

19. Milne K, Kobel M, Kalloger SE, Barnes RO, Gao D, et al. (2009) Systematic analysis of immune infiltrates in high-grade serous ovarian cancer reveals CD20, FoxP3 and TIA-1 as positive prognostic factors. PLoS One 4: e6412. [Crossref]

20. Mahmoud SM, Lee AH, Paish EC, Macmillan RD, Ellis IO, et al. (2012) The prognostic significance of B lymphocytes in invasive carcinoma of the breast. Breast Cancer Res Treat 132: 545-553. [Crossref]

21. Ammirante M, Luo JL, Grivennikov S, Nedospasov S, Karin M (2010) B-cell- derived lymphotoxin promotes castration-resistant prostate cancer. Nature 464: 302-305. [Crossref]

22. Inoue S, Leitner WW, Golding B, Scott D (2006) Inhibitory effects of B cells on antitumor immunity. Cancer Res 66: 7741-7747. [Crossref]

23. Qin Z, Richter G, Schüler T, Ibe S, Cao X, et al. (1998) B cells inhibit induction of T cell-dependent tumor immunity. Nat Med 4: 627-630. [Crossref]

24. Chapoval AI, Fuller JA, Kremlev SG, Kamdar SJ, Evans R (1998) Combination chemotherapy and IL-15 administration induce permanent tumor regression in a mouse lung tumor model: NK and T cell-mediated effects antagonized by B cells. J Immunol 161: 6977-1984. [Crossref]

25. Mizoguchi A, Mizoguchi E, Takedatsu H, Blumberg RS, Bhan AK (2002) Chronic intestinal inflamma- tory condition generates IL-10-producing regulatory B cell subset characterized by CD1d upregulation. Immunity 16: 219-230. [Crossref]

26. Schioppa T, Moore R, Thompson RG, Rosser EC, Kulbe H, et al. (2011) B regulatory cells and the tumor-promoting actions of TNF-alpha during squamous carcinogenesis Proc Natl Acad Sci U S A 108: 10662-10667. [Crossref]

27. Horikawa M, Minard-Colin V, Matsushita T, Tedder TF (2011) Regulatory B cell production of IL-10 inhibits lymphoma depletion during CD20 immunotherapy in mice. J Clin Invest 121: 4268-4280. [Crossref]

28. Tadmor T, Zhang Y, Cho HM, Podack ER, Rosenblatt JD (2011) The absence of B lymphocytes reduces the number and function of T-regulatory cells and enhances the anti-tumor response in a murine tumor model. Cancer Immunol Immunother 60: 609619. [Crossref]

Copyright: (C2019 Goret NE. This is an open-access article distributed under the terms of the Creative Commons Attribution License, which permits unrestricted use, distribution, and reproduction in any medium, provided the original author and source are credited. 